Legal Theory is a quarterly, peer-reviewed journal that is edited to the highest standards with the assistance of a prestigious international editorial board. Like other peer-reviewed journals, Legal Theory has an exclusive submission policy and will consider only manuscripts that have not been previously published and that are not being considered for publication elsewhere. Authors should, upon submission, confirm that their essays have not been previously published and are not undergoing review by another publication.

Legal Theory publishes work on a broad range of topics, including but not limited to analytical jurisprudence, normative jurisprudence, policy analyses of legal institutions and doctrines, theories of law as a social or cultural phenomenon, and critical perspectives on law and legal institutions. Although Legal Theory especially seeks articles that make a positive original contribution, submissions directly commenting on other works in the existing literature are welcome.

Anonymized articles should be submitted via ScholarOne at https://mc.manuscriptcentral.com/leg. Authors should not contact the editors directly about whether Legal Theory might be interested in their articles.

Preparation of manuscript. A separate title page should be prepared including the article title, short title for use as a running head (not to exceed 45 characters), author's full name and affiliation, and complete contact information (including phone number and e-mail address).

Manuscripts should be prepared for blind review by external reviewers, with any information that might identify the author removed.

Manuscripts should be submitted in Word and should conform to Chicago style (however, see below concerning preparation of reference and note material).

Manuscripts should be shorter than 15,000 words exclusive of notes. A separate abstract of no more than 150 words should be included. Short comments (4,500 words or less, excluding reference and note material) on articles that have appeared in Legal Theory will undergo expedited review by the editors, with additional external review where this is deemed necessary.

The entire manuscript (including notes and references) should be typed double-spaced with wide margins for copyediting. Manuscript pages should be numbered consecutively. Authors of accepted articles will be asked to prepare a final version in the journal's style.

References and notes. References should conform to the most recent edition of The Bluebook: A Uniform System of Citation.

Pre-submission English-language editing. Authors, particularly those whose first language is not English, may wish to have their English-language manuscripts checked by a native speaker before submission. This is optional, but may help to ensure that the academic content of the paper is fully understood by the editor and any reviewers. Cambridge University Press offers a language-editing service in conjunction with a third-party provider American Journal Experts: http://www. cambridge.org/academic/author-services/ Please note that use of this service is voluntary, and at the author's own expense. Use of this service does not guarantee that the manuscript will be accepted for publication, nor does it restrict the author to submitting to a Cambridge published journal. Cambridge is providing this service in order to provide a convenient option for prospective authors, which comes with the reassurance that we have checked the quality of the provider, and will be continuously monitoring the quality of the service.

Figures. If the manuscript is accepted for publication, the author must provide figures that are ready for photographic reproduction; they cannot be redrawn by the publisher, unless the author pays for the cost of such work. Charts, graphs, or other artwork must be drawn by a professional artist or computer generated on a laser printer, in black ink on white paper, and should remain legible after a $50 \%$ reduction. All labels and details on figures should be clearly printed. Full information on how to prepare and supply figures, tables and graphics can be found here and should be followed with care.

Color. Charges apply for all color figures that appear in the print version of the journal. At the time of submission, contributors should clearly state whether their figures should appear in color in the online version only, or whether they should appear in color online and in the print version. There is no charge for including color figures in the online version of the Journal but it must be clear that color is needed to enhance the meaning of the figure, rather than simply being for aesthetic purposes. If you request color figures in the printed version, you will be contacted by CCC-Rightslink who are acting on our behalf to collect Author Charges. Please follow their instructions in order to avoid any delay in the publication of your article.

Copyright and submission conditions. Submitting an article to Legal Theory implies that it has not been published elsewhere and is not being considered for publication elsewhere. Authors must obtain written permission to publish any material for which they do not own copyright. They will be asked to assign the copyright of their article, under certain conditions, to Cambridge University Press. Offprints may be purchased if ordered at proof stage on the form provided.

Copyediting and proofreading. The publisher reserves the right to copyedit and proofread all articles accepted for publication, but authors will be consulted in the case of any substantial changes. Page proofs of each article will be sent to the lead author for correction of typographical errors only.

Open Access. Legal Theory encourages authors to take full advantage of its flexible Green Open Access policy. The Submitted Manuscript may be posted on a personal webpage, departmental, institutional or subject repository or social media site at any time. The Accepted Manuscript may be posted on a personal webpage, departmental, institutional or non-commercial subject repository immediately on acceptance. While the journal does not allow the posting of the Accepted Manuscript on commercial repositories or the Version of Record anywhere, we encourage authors to post an earlier draft and abstract of their journal article and a link to the Version of Record that sits on the Cambridge website, to direct visitors to the definitive, citable work. Full details of this policy can be found in the Copyright Transfer Form. Please visit https://www.cambridge.org/core/services/open-access-policies for further information on our open access policies, compliance with major funding bodies, and guidelines on depositing your manuscript in an institutional repository. 


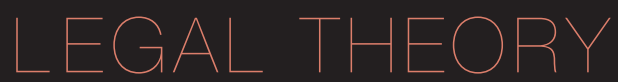

159 Wirtbarkeit: Cosmopolitan Right and Innkeeping Aravind Ganesh

191 Obeying The Law

Michael Sevel

216 Reasoning by Precedent-Between Rules and Analogies

\section{Katharina Stevens}

Cambridge Core

For further information about this journal please go to the journal web site at cambridge.org/leg 